\title{
Roles of leaf in regulation of root and shoot growth from single node softwood cuttings of grape (Vitis vinifera)
}

\author{
By PIOUS THOMAS*1 and JOHN W SCHIEFELBEIN \\ Department of Molecular, Cellular and Developmental Biology, The University of Michigan, Ann Arbor, \\ MI 48109-1048, USA
}

(Accepted 11 July 2003; Received 25 March 2003)

\begin{abstract}
Summary
The role of leaf in regulation of root and shoot growths in single node softwood cuttings of grape (Vitis vinifera) was characterised. Leafy cuttings showed early rooting, vigorous root growth and subsequent shoot development. Defoliation at planting induced early sprouting, but adversely affected rooting and decreased the survival of cuttings irrespective of pre-planting treatment with $100 \mu \mathrm{M}$ indole 3-acetic acid (IAA). Treatment with IAA did not affect the percent rooting of leafy cuttings but increased root and shoot growth. Leaf weight (wt) and leaf area of the cuttings showed a highly significant correlation to root wt of the new plant at $4 \mathrm{wk}$ after planting, while cutting stem + petiole wt was either not or less significantly correlated to root and shoot weights of the subsequent plant. The greater the area or wt of leaf, the better the root and shoot growths, implying that leaf contributed to adventitious root growth. However, retaining the leaf for just 2 days was enough to stimulate rooting in more than $80 \%$ of the cuttings, suggesting that leaf tissue could also induce root formation. Root growth increased with the period of leaf retention but leaf removal before 3 wk triggered sprouting leading to high mortality in rooted cuttings. Bringing the leaf closer to the rooting zone by preparing leaf at base (LAB) cuttings delayed rooting and sprouting compared with the standard leaf at top (LAT) cuttings. An inhibitory effect on rooting and sprouting by the exposed upper internode region in LAB cuttings is suggested.
\end{abstract}

Key words: Adventitious rooting, auxin, grape, IAA, leaf, propagation, softwood cutting, Vitis vinifera

Abbreviations: LAB, single node cutting with a leaf at the basal end; LAT, single node cutting with a leaf at the top end; $\mathrm{L}^{+}$, leafy cutting; $\mathrm{L}$; defoliated cutting; IAA, indole 3-acetic acid; IBA, indole 3butyric acid; DAP, days after planting; WAP, weeks after planting.

\section{Introduction}

Leaves and buds on cuttings benefit rooting in some species and types of cuttings (Van Overbeek et al., 1946; Dore, 1965; Fournioux, 1997), while the absence of leaves has been fatal in certain instances (Dore, 1965; Wilson, 1994). Leaf supplies indole 3-acetic acid (IAA), vitamins, carbohydrates, organic nitrogen and rooting cofactors that are required for rooting (Dore, 1965; Jarvis, 1986). Many studies using leafy cuttings have dealt with the role of leaf in regulation of rooting, but little attention has been paid to leaf as a regulator of shoot growth.

Grape (Vitis sp.) is conventionally propagated using dormant hardwood cuttings collected from current season's canes during winter (Hartmann et al., 1997). This is a slow process for the multiplication of new cultivars or elite types. Micropropagation has offered great potential for rapid propagation of grape (Barlass \& Skene, 1980;
Thomas, 1997) but this approach demands technical expertise and controlled conditions. Greenwood leafy cuttings with bottom heat and mist are used for propagation of scarce planting material such as virus indexed stocks (Hartmann et al., 1997). In order to achieve fast multiplication of an introduced grape (V. vinifera L.) cv. Arka Neelamani, we evolved a combination of in vitro and in vivo propagation approaches (Thomas \& Schiefelbein, 2001). In vitro approaches included induction of root and shoot growth in shoot tip and nodal microcuttings in IAA (1 $\mu \mathrm{M})$ supplemented Murashige \& Skoog (1962) medium, sequential pruning of shoots at $1,1.5$ and 2 months leaving the basal one to two nodes, subculturing of fresh sprouts, and use of leftover stumps for in vivo establishment. In vivo propagation involved the use of single node cuttings from 1.5 to 2 month old in vivo shoots as well as fresh sprout growth from these cuttings for the subsequent propagation. Leafy cuttings in vivo gave vigorous root and shoot growth but the lamina restricted the 
number of cuttings per unit area. Use of defoliated cuttings resulted in very poor rooting and survival although they exhibited high initial sprouting.

Thus, leafy softwood cuttings allowed rapid propagation of elite grapes, while defoliation appeared to have potential as a method to investigate physiological and molecular bases of regulation of root and shoot growths, and to study recalcitrance to rooting in stem cuttings without any interfering genotypic influences. The objectives of the present studies were to quantify the role of leaf in regulation of root and shoot growth in softwood cuttings and to characterise the response of leafy and defoliated cuttings.

\section{Materials and Methods}

The studies were carried out using single-node softwood cuttings from 2 month old in vivo established, tissue culture derived plants of grape (Vitis vinifera L.) cv. Arka Neelamani and the shoots from leafy single-node cuttings further propagated in vivo (Thomas \& Schiefelbein, 2001) unless mentioned otherwise. These plants were raised at $26 \pm 2^{\circ} \mathrm{C}$ under $16 \mathrm{~h}$ photoperiod $\left(60-80 \mu \mathrm{mol} \mathrm{m}^{-2} \mathrm{~s}^{-1}\right)$ provided by cool-white fluorescent tubes (Sylvania, USA). They grew $20-30 \mathrm{~cm}$ tall with about 2-4 closely spaced nodes towards the base, 4-6 green large leaf-bearing nodes and 1-2 tender, coloured, terminal leafy nodes. Keeping the lamina at top end (LAT) of the cutting, four cuttings were prepared from the second category per stock shoot and were segregated to four groups based on their positions on the stock shoot. One cutting from each of the four groups was planted in a mini pot $(8 \mathrm{~cm} \times 8 \mathrm{~cm}$ $\times 7.5 \mathrm{~cm}$ ) in Sunshine Mix $1{ }^{\circledR}$ (Sungrow Horticulture, Washington DC, USA), to give four plants per pot. One pot constituted a single replication in all the experiments. Before planting, the lower half of all the cuttings were dipped for $10 \mathrm{~min}$ in $100 \mu \mathrm{M}$ IAA prepared in half strength Murashige \& Skoog (1962) medium ( $\mathrm{pH}$ 6.0), unless mentioned otherwise. The pots were arranged in plastic trays and covered with transparent domes to avoid desiccation. The incubation conditions were the same as for the stock plants. The domes were partly opened after $2 \mathrm{wk}$ and fully after $3 \mathrm{wk}$.

\section{Effect of defoliation}

The cuttings were planted with the leaf intact $\left(\mathrm{L}^{+}\right.$ cutting) or after defoliation retaining the petiole ( $\mathrm{L}^{-}$ cutting). At 1 wk after planting (WAP), the cuttings were lifted and observed for any signs of rooting (basal swelling or root emergence) and were replanted avoiding any damage to roots. At 4 WAP, percent survival, rooting, sprouting, height (ht) and fresh weight (wt) of the sprout, and number, mean length, and fresh wt of the roots were recorded. Root variables were recorded after washing and blotting the tissue using paper towels. There were 12 replicates in this experiment.

A similar experiment with 12 replicates was carried out using single-node softwood cuttings derived from actively growing shoots of an undesignated field vine during spring (May-June).

In a subsequent experiment, the difference in dry wt of $\mathrm{L}^{+}$and $\mathrm{L}^{-}$cuttings of cv. Arka Neelamani was determined between the time of planting and 5 days after planting (DAP), before any visible root emergence in leafy cuttings or the onset of decay in $\mathrm{L}^{-}$cuttings. This was to see if dry matter accumulation occurred during this period. To minimise any error due to differences in initial wt of the cuttings, the cuttings in both treatments were grouped into pairs of similar fresh wt, one of which was used for dry wt determination at planting and the other on the fifth day. A replicate in this experiment did not consist of four cuttings in a pot. Instead, 36 leafy cuttings were weighed individually and grouped into 18 pairs of similar weight. One cutting of the pair was used for dry wt determination that same day and the other 5 DAP. Net assimilation was worked out as the difference in dry wt. The same procedure was done with 36 defoliated cuttings.

\section{Influence of weight or leaf area of cuttings on root and shoot growth}

In order to elucidate whether a correlation existed between the wt or leaf area of the cutting and the root and shoot growths from it, wt of the cutting was recorded at planting in an experiment comprising 72 leafy cuttings from 18 replicate minipots. At 4 WAP, growth indicators (root number and $\mathrm{wt}$, sprout ht and wt) were recorded from the 65 new plants that resulted. Measurements were also made on the parts of the plant that corresponded morphologically to the original cutting (total wt, leaf $\mathrm{wt}$, stem + petiole wt, leaf area), as it was not possible to make all these measurements at planting. Leaf area was recorded using LI-3000 LICOR model leaf area meter (LI-COR, Inc., Lincoln, NE, USA). Correlation coefficients $(r)$ between wt of the cuttings at planting and wt at 4 WAP, and between morphological measurements corresponding to the original cutting and growth indicators of the new plant were determined. A similar experiment was carried out using 32 cuttings that were given a preplanting 10 min treatment in $100 \mu \mathrm{M}$ indole 3-butyric acid (IBA) instead of IAA.

\section{Rooting without auxin supplementation}

In order to see the effect of auxin on rooting, $\mathrm{L}^{+}$ and $\mathrm{L}^{-}$cuttings were planted with or without the standard 10 min dip treatment in $100 \mu \mathrm{M}$ IAA. There were eight replicates per treatment and observations on root and shoot growths were recorded at 4 WAP. 
In a subsequent experiment, $r$ between different morphological variables of the cutting and the growth indicators of new plants at 4 WAP were determined using 16 cuttings that were not given pre-planting IAA treatment.

\section{Effect of decrease in leaf area}

To see if retention of part of the leaf could influence the survival and root and shoot growth from cuttings, three treatments with decreased leaf area were tried. These were retaining (i) longitudinal half segment including the midrib, (ii) transverse leaf segment between the point of petiole attachment and the sinus end and (iii) a piece of leaf $1 \mathrm{~cm} \times 1 \mathrm{~cm}$ at the point of petiole attachment. Standard $\mathrm{L}^{+}$and $\mathrm{L}^{-}$ cuttings served as controls. There were four replicates per treatment. Cutting wt was recorded at the time of planting. Rooting was recorded at $1 \mathrm{WAP}$, while data on survival and sprouting were recorded at weekly intervals. At 4 WAP, root and shoot growth indicators of the new plants were recorded. An additional trial with six replicates was done using cuttings with a segment of $0.5 \mathrm{~cm} \times 0.5 \mathrm{~cm}$ lamina or just the barest minimum lamina at petiole end (approx. $0.1 \mathrm{~cm} \times 0.1 \mathrm{~cm}$ ).

\section{Effect of leaf retention for different periods}

To see if leaf retention for shorter periods could induce rooting in stem cuttings, lamina were removed 2, 4, 7, 14 or 21 DAP. Controls were standard $\mathrm{L}^{+}$and $\mathrm{L}^{-}$cuttings. Cuttings were not given auxin treatment before planting. Observations on various morphological measurements of the original cuttings and growth indicators of the new plants were recorded as earlier. There were eight replicates per treatment.

\section{Effect of bringing the leaf closer to the rooting zone}

In order to see if bringing the leaf closer to the basal end of the cutting where the rooting is often localised could influence root and shoot growth, single node cuttings were prepared with the full upper inter-node segment and the leaf at the base (LAB). Observations on root and shoot growth were made in comparison with LAT cuttings. There were 20 replicates per treatment.

A separate experiment using 20 plants per treatment was done to confirm the differential response of $\mathrm{LAB}$ cuttings towards sprouting. In this experiment, 1.5-2 month old in vivo plants were cutback just above or below a node about $12-15 \mathrm{~cm}$ above the collar region to give situations similar to that observed in LAT and LAB cuttings.

\section{Statistical treatments}

The data were analysed for single factor variance (completely randomised design) using Microsoft
Excel 98, unless otherwise stated. Percent data were subjected to arc-sine transformation before analysis of variance (ANOVA), if appropriate. Formal ANOVA is not valid where a majority of individual values are $0 \%$ or $100 \%$, so analyses are not presented in those cases. Other variates were log-transformed to stabilise the variance, if required. Where treatments gave different numbers of plants due to effects on survival, this was dealt with by using unequal replications. In the experiment on estimation of dry matter accumulation between planting and day 5 in $\mathrm{L}^{+}$and $\mathrm{L}^{-}$cuttings, the data were subjected to ANOVA for two factor variance (randomised block design) to nullify the effect due to difference in initial wt of the cuttings. Correlation coefficients between different variables were also worked out using MS Excel. Unless otherwise stated, 'significant' refers to a threshold of $P<0.05$. Symbols *,** and $* * *$ in tables indicate significance at $P<0.05,<0.01$ and $<0.001$, respectively, while NS indicates $P>0.05$.

\section{Results}

\section{Effect of defoliation}

The $\mathrm{L}^{-}$cuttings showed an earlier start to shoot growth and gave $75 \%$ sprouting at $1 \mathrm{WAP}$, while $\mathrm{L}^{+}$ cuttings showed only $4 \%$ sprouting (Fig. 1). Basal swelling or signs of root initiation was evident in $85 \%$ of $\mathrm{L}^{+}$cuttings, while only $19 \%$ of $\mathrm{L}^{-}$cuttings exhibited any basal swelling. Survival of $L^{-}$cuttings declined from $96 \%$ at $1 \mathrm{WAP}$ to $10 \%$ at $4 \mathrm{WAP}$ and any surviving ones were of basal origin on the stock shoot. None of the L- cuttings resulted in a healthy plant. The $\mathrm{L}^{+}$cuttings on the other hand showed slow sprouting, good survival and high output of healthy plantlets at 4 WAP (92\%) with healthy root growth (Fig. 2; Table 1). Similar effects of defoliation were observed in cuttings from the field-grown vine (Table 1).

The $\mathrm{L}^{+}$cuttings of 'Arka Neelamani' showed a significant increase in dry wt from $92 \mathrm{mg}$ at planting to $104 \mathrm{mg} 5 \mathrm{DAP}$, with $89 \%$ of the cuttings displaying an increase in wt. A majority $(66 \%)$ of the $\mathrm{L}^{-}$cuttings showed a drop in dry wt between planting and $5 \mathrm{DAP}$, although the difference was not significant.

\section{Influence of weight or leaf area of cuttings on root and shoot growths}

At the time of planting, the leafy cuttings weighed 700-800 mg (Table 2A). At 4 WAP, the cuttings showed a mean increase in wt of $23 \%$ and $41 \%$ in IAA- and IBA-treated sets. The lamina constituted about $55-65 \%$, the petiole $8-10 \%$ and the stem the rest of the total wt of a cutting. The IBA-treated cuttings recorded greater root wt than IAA-treated ones, but other growth indicators did not differ 
significantly.

All the morphological variables recorded at 4 WAP that correspond to the original cutting (total wt, leaf $\mathrm{wt}$, stem + petiole wt and leaf area) showed significant $(P<0.001)$ correlations with wt of cuttings at planting $(r=0.93,0.91,0.92$ and 0.87 , respectively, in IAA-treated cuttings, and $r=0.60$, $0.66,0.56$ and 0.63 in IBA-treated cuttings). The individual morphological variables of the cuttings recorded at 4 WAP exhibited significant correlation amongst them $(P<0.01$ in all cases; data not presented).

IAA-treated cuttings exhibited significant correlation between wt at planting and root wt, sprout wt, sprout height and root number at 4 WAP, while IBA-treated cuttings displayed a less significant correlation with these variables particularly in respect of root number (Table 2B). Total root wt per plant showed significant correlation with all

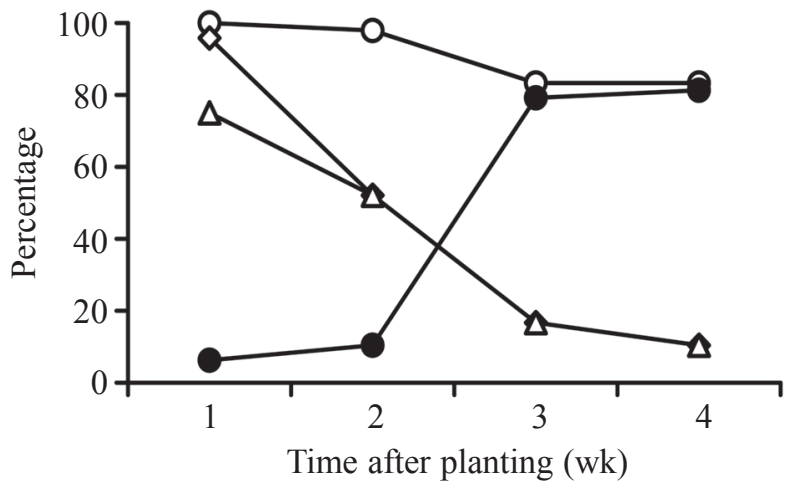

Fig. 1. Percent survival and sprouting in IAA-treated leafy $\left(\mathrm{L}^{+}\right)$and defoliated $\left(\mathrm{L}^{-}\right)$softwood cuttings of grape during the 4 wk period after planting.

$\mathrm{O}=\mathrm{L}^{+}$survival; $\diamond=\mathrm{L}^{-}$survival

$\widehat{O}=\mathrm{L}^{+}$sprouting; $\triangle=\mathrm{L}^{-}$sprouting individual variables of IAA-treated cuttings at 4 WAP and they ranked in the order leaf area, total wt of cuttings, wt of leaf and wt of stem + petiole based on the level of significance of correlation coefficient. This order for IBA-treated cuttings was total wt of the cutting, leaf wt, leaf area and wt of stem + petiole.

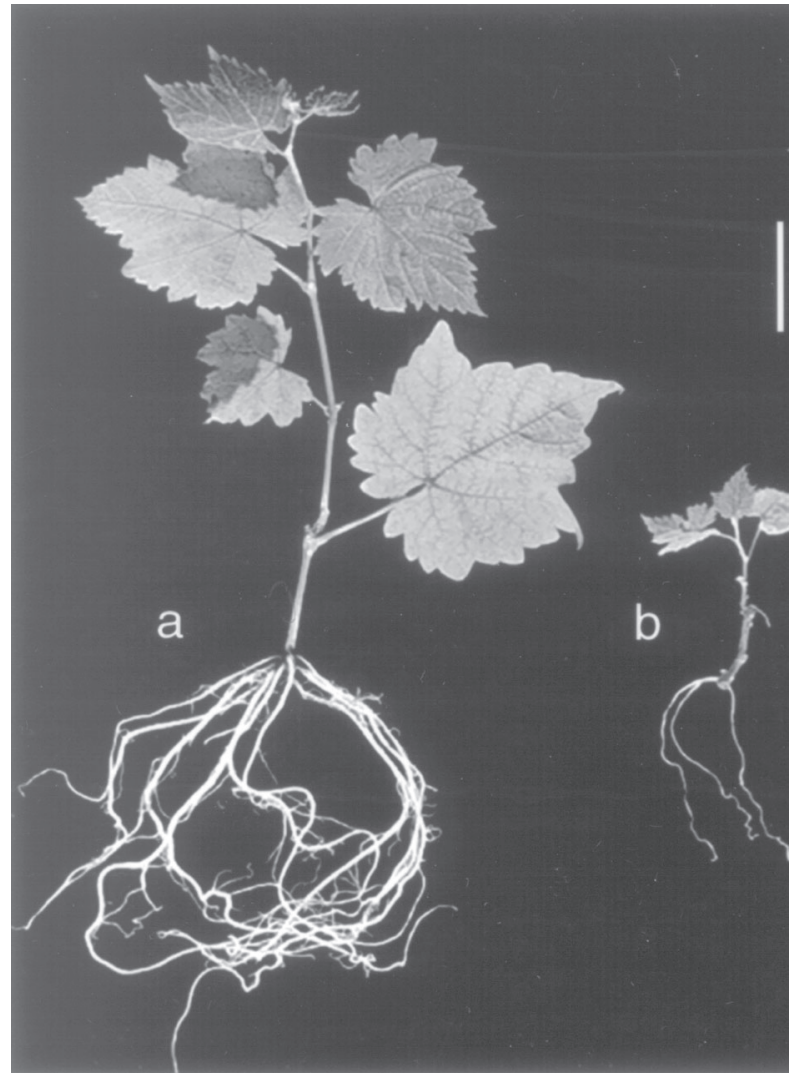

Fig. 2. Performance of IAA-treated leafy (a) and defoliated (b) surviving softwood cuttings of grape at $4 \mathrm{wk}$ after planting $(\mathrm{Bar}=3 \mathrm{~cm})$.

Table 1. Performance of leafy $\left(L^{+}\right)$and defoliated $\left(L^{-}\right)$softwood nodal cuttings of grape cv. 'Arka Neelamani' or a field-grown vine at 4 wk after planting, showing means or back-transformed means. Values in parenthesis indicate means and SED on logarithmic transformed scale. Analysis of variance was not appropriate for variables 1 and 2 due to the high proportion of $0 \%$ and $100 \%$ values

\begin{tabular}{|c|c|c|c|c|c|c|c|c|c|c|}
\hline \multirow[b]{2}{*}{ Variable } & \multicolumn{5}{|c|}{ Arka Neelamani } & \multicolumn{5}{|c|}{ Field vine } \\
\hline & $\mathrm{L}^{+}$ & $\mathrm{L}^{-}$ & Significance & SED & $\mathrm{df}$ & $\mathrm{L}^{+}$ & $\mathrm{L}^{-}$ & Significance & SED & $\mathrm{df}$ \\
\hline 1. Survival of cuttings $(\%)$ & 94 & 10 & & & & 92 & 6 & & & \\
\hline 2. Cuttings with root and shoot growth (\%) & 92 & 2 & & & & 90 & 4 & & & \\
\hline 3. Sprout ht $(\mathrm{cm})$ & 6.5 & 2.0 & ** & 1.37 & 12 & 11.8 & 1.0 & $* * *$ & 2.32 & 13 \\
\hline \multirow[t]{2}{*}{ 4. Sprout wt (mg) } & 494 & 70 & & & 12 & 687 & 30 & & & \\
\hline & $(6.1)$ & $(3.4)$ & $* *$ & $(0.52)$ & & $(6.4)$ & $(3.4)$ & $* *$ & $(0.33)$ & 13 \\
\hline \multirow[t]{2}{*}{ 5. Root number } & 7.1 & 2.5 & & & 13 & 9.1 & 1.5 & & & \\
\hline & $(2.0)$ & $(1.1)$ & $* * *$ & $(0.18)$ & & $(2.2)$ & $(0.9)$ & $* * *$ & $(0.29)$ & 12 \\
\hline 6. Mean root length plant ${ }^{-1}(\mathrm{~cm})$ & 11.7 & 3.7 & $* * *$ & 1.37 & 13 & 10.8 & 3.1 & $* * *$ & 1.36 & 12 \\
\hline \multirow[t]{2}{*}{ 7. Root fresh wt (mg) } & 1090 & 28 & & & & 1160 & 12.6 & & & \\
\hline & $(6.9)$ & $(3.1)$ & $* * *$ & $(0.23)$ & 13 & $(7.0)$ & $(2.6)$ & $* * *$ & $(0.21)$ & 12 \\
\hline
\end{tabular}


The results in both cases indicated that the leaf component was more important than stem + petiole components of the cuttings in root growth.

The sprout wt showed a significant correlation with different variables of IAA-treated cuttings at 4 WAP. IBA-treated cuttings showed no significant correlations, except with leaf wt. The sprout wt was significantly correlated to root wt in both instances. As sprouting took place after rooting in leafy cuttings, it seemed that sprout vigour was a reflection of root vigour. A significant correlation also existed between root wt and sprout ht in IAA-treated cuttings but not in the case of IBA treated cuttings that showed more root growth and relatively thicker shoots.

\section{Rooting without auxin supplementation}

Omitting IAA treatment before planting leafy cuttings did not significantly affect rooting or percent sprouting at 1 WAP. At 4 WAP, previous IAA treatment did not significantly affect survival, rooting, \% sprouting, root number and root length (data not shown). However, root wt per cutting was significantly greater in IAA-treated cuttings (1911 $\mathrm{mg}$ and $847 \mathrm{mg}$ respectively; $P<0.01$ ) which resulted from an increase in the wt of individual roots (351 $\mathrm{mg}$ and $168 \mathrm{mg}$ respectively; $P<0.01$ ), rather than increase in number or length of the roots. IAAtreated cuttings also showed significantly $(P<0.01)$ greater sprout wt and ht, which probably resulted from better root growth. Omitting IAA treatment increased the survival of defoliated cuttings from $10 \%$ to $25 \%$, although this increase was not significant.

Leafy cuttings not treated with IAA displayed significant correlations between different morphological variables of the original cuttings and root and shoot growth at $4 \mathrm{WAP}$, although there was no significant correlation with stem + petiole wt (Table 3).

\section{Effect of decrease in leaf area}

It was observed 1 WAP that the leaf part in treatments with partial lamina remained green in spite of the injury. A decrease in leaf area led to an increase in sprouting at 1 WAP (Table 4). However, the orientation of the remaining leaf part also affected sprouting, with transverse leaf segment (TLS)

Table 2. Mean values of variables of softwood cuttings of grape treated with IAA or IBA at planting, growth indicators recorded at 4 wk after planting, and correlation coefficient $(r)$ between selected variables

A. Mean

\begin{tabular}{|c|c|c|c|}
\hline \multirow[b]{2}{*}{ No. } & \multirow[b]{2}{*}{ a. Independent factors - Cutting variables } & \multicolumn{2}{|c|}{ Treatment } \\
\hline & & IAA & IBA \\
\hline 1. & Wt of cuttings at planting $(\mathrm{mg})$ & 782 & 708 \\
\hline 2. & Wt of original cutting at 4 WAP (mg) & 961 & 997 \\
\hline 3. & Wt. of stem + petiole at 4 WAP $(\mathrm{mg})$ & 401 & 381 \\
\hline 4. & Wt of leaf lamina at $4 \mathrm{WAP}(\mathrm{mg})$ & 568 & 626 \\
\hline \multirow[t]{2}{*}{5.} & Leaf area of cutting at 4 WAP $\left(\mathrm{cm}^{2}\right)$ & 39 & 45 \\
\hline & b. Dependent factors - Plant variables at 4 wk & & \\
\hline 6. & Root fresh wt (mg) & 1558 & 2059 \\
\hline 7. & Root number & 6.7 & 5.2 \\
\hline 8. & Fresh wt of sprout (mg) & 787 & 963 \\
\hline 9. & Height of sprout $(\mathrm{cm})$ & 8.8 & 10.3 \\
\hline
\end{tabular}

B. Correlation coefficient (r)

\begin{tabular}{|c|c|c|c|c|c|c|c|c|c|c|c|c|c|c|}
\hline \multirow{3}{*}{ 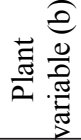 } & \multicolumn{7}{|c|}{ IAA treated cuttings ${ }^{\alpha}$} & \multicolumn{7}{|c|}{ IBA treated cuttings ${ }^{\beta}$} \\
\hline & \multicolumn{5}{|c|}{ Cutting variable (a) } & \multicolumn{2}{|c|}{ Plant variable (b) } & \multicolumn{5}{|c|}{ Cutting variable (a) } & \multicolumn{2}{|c|}{ Plant variable (b) } \\
\hline & 1 & 2 & 3 & 4 & 5 & 6 & 8 & 1 & 2 & 3 & 4 & 5 & 6 & 8 \\
\hline \multirow[t]{2}{*}{6} & 0.80 & 0.84 & 0.78 & 0.83 & 0.86 & 1.0 & 0.78 & 0.54 & 0.86 & 0.71 & 0.84 & 0.71 & 1.0 & 0.35 \\
\hline & $* * *$ & $* * *$ & $* * *$ & $* * *$ & ${ }^{* * *}$ & $* * *$ & $* * *$ & ** & $* * *$ & $* * *$ & *** & $* * *$ & *** & * \\
\hline \multirow[t]{2}{*}{7} & 0.56 & 0.34 & 0.26 & 0.34 & 0.20 & 0.14 & 0.02 & 0.03 & 0.34 & 0.26 & 0.35 & 0.35 & 0.29 & 0.16 \\
\hline & $* * *$ & ** & * & ** & NS & NS & NS & NS & NS & NS & * & $*$ & NS & NS \\
\hline \multirow[t]{2}{*}{8} & 0.71 & 0.66 & 0.64 & 0.59 & 0.61 & 0.78 & 1.0 & 0.49 & 0.34 & 0.29 & 0.37 & 0.31 & 0.35 & 1.0 \\
\hline & $* * *$ & $* * *$ & $* * *$ & $* * *$ & $* * *$ & $* * *$ & $* * *$ & $* *$ & NS & NS & * & NS & * & $* * *$ \\
\hline \multirow[t]{2}{*}{9} & 0.59 & 0.58 & 0.56 & 0.53 & 0.57 & 0.73 & 0.94 & 0.39 & 0.27 & 0.19 & 0.27 & 0.29 & 0.22 & 0.90 \\
\hline & $* * *$ & $* * *$ & $* * *$ & $* * *$ & $* * *$ & $* * *$ & $* * *$ & $*$ & NS & NS & NS & NS & NS & $* * *$ \\
\hline
\end{tabular}

$\alpha_{\mathrm{df}}=63 ; \beta_{\mathrm{df}}=27$ 
cuttings giving greater sprouting than longitudinal leaf segment (LLS) cuttings. The presence of leaf tissue promoted rooting $1 \mathrm{WAP}$, with little difference between the leaf treatments (Table 4).

At 4 WAP, the presence of leaf tissue on the cutting greatly improved survival, rooting and sprouting, even with only a $1 \mathrm{~cm} \times 1 \mathrm{~cm}$ segment of leaf present (Table 4). The leaf area of the original cutting had little effect on root number, as long as some leaf

Table 3. Correlation between different morphological variables of leafy cuttings (no IAA treatment) at 4 wk after planting, and root or shoot fresh $w t$

\begin{tabular}{lcc}
\hline & \multicolumn{2}{c}{ Plant variable } \\
Cutting variable & Root wt & Sprout wt \\
\hline Leaf area & $0.868^{* *}$ & $0.662^{* *}$ \\
Leaf wt & $0.764^{* *}$ & $0.574^{*}$ \\
Total wt & $0.732^{* *}$ & $0.590^{*}$ \\
Stem + petiole wt & $0.344^{\mathrm{NS}}$ & $0.325^{\mathrm{NS}}$ \\
df $=14$ & & \\
\hline
\end{tabular}

tissue was present. On the other hand, total root wt, shoot ht and shoot wt appeared to be almost proportional to the area of the leaf retained on the cutting (Table 4, Fig. 3a-e). The cuttings showed expansion of any retained leaf segments, as indicated by increase in leaf area of cuttings with $1 \mathrm{~cm} \times 1 \mathrm{~cm}$ leaf segment to $4 \mathrm{~cm}^{2}$ at 4 WAP.

In the next experiment, cuttings retained with 0.5 $\mathrm{cm} \times 0.5 \mathrm{~cm}$ leaf segment or a barest minimum leaf at the petiole tip showed significantly greater survival and rooting at 4 WAP than defoliated cuttings $(50 \%$ for both leaf treatments, compared with $8 \%$ ). While the root number in surviving cuttings was unaffected by the leaf area $(2.8,2.9$ and 2.0 respectively, $P>0.05)$, the root wt $(85,65$ and $20 \mathrm{mg}$ per plant, respectively) and sprout wt (73, 36 and $25 \mathrm{mg}$, respectively) increased with leaf area (see also Fig. 3x-y).

Effect of leaf retention for different periods

Defoliation of cuttings 0,2 , or 4 DAP, gave sprouting 1 WAP of $91 \%, 53 \%$ and $47 \%$,

Table 4. Effect of reduction in leaf area on root and shoot growth in softwood cuttings of grape cv. Arka Neelamani. Observations are at 4 wk after planting unless otherwise stated. Values in parenthesis indicate means and SED on transformed scale. LLS indicates cutting with longitudinal leaf segment, TLS indicates cutting with transverse leaf segment. Analysis of variance was not appropriate for variables 3 to 6 due to the high proportion of $0 \%$ and $100 \%$ values

\begin{tabular}{|c|c|c|c|c|c|c|c|c|}
\hline \multirow[b]{2}{*}{$\begin{array}{l}\text { Growth/physiological variables } \\
\text { of cuttings used }\end{array}$} & \multicolumn{5}{|c|}{ Treatment } & \multirow[b]{2}{*}{ Significance } & \multirow[b]{2}{*}{ SED } & \multirow[b]{2}{*}{$\mathrm{df}$} \\
\hline & Full leaf & LLS & TLS & $\begin{array}{c}1 \mathrm{~cm} \times 1 \\
\mathrm{~cm} \text { lamina }\end{array}$ & No leaf & & & \\
\hline 1. Wt at planting (mg) & 781 & 480 & 356 & 259 & 205 & $* * *$ & 30.3 & 15 \\
\hline 2. Sprouting at $1 \mathrm{wk}(\%)$ & $\begin{array}{c}6 \\
(7.5)\end{array}$ & $\begin{array}{c}13 \\
(11.2)\end{array}$ & $\begin{array}{c}44 \\
(41.2)\end{array}$ & $\begin{array}{c}56 \\
(48.7)\end{array}$ & $\begin{array}{c}75 \\
(72.5)\end{array}$ & $* *$ & $(13.60)$ & 15 \\
\hline 3. Rooting at $1 \mathrm{wk}(\%)$ & 75 & 75 & 75 & 75 & 6 & & & \\
\hline 4. Survival at 4 wk (\%) & 100 & 100 & 100 & 94 & 6 & & & \\
\hline 5. Rooting at 4 wk (\%) & 100 & 100 & 100 & 94 & 6 & & & \\
\hline 6. Sprouting at $4 \mathrm{wk}(\%)$ & 100 & 88 & 94 & 94 & 6 & & & \\
\hline 7. Roots per cutting & $\begin{array}{c}5.9 \\
(1.84)\end{array}$ & $\begin{array}{c}4.0 \\
(1.50)\end{array}$ & $\begin{array}{c}5.5 \\
(1.76)\end{array}$ & $\begin{array}{c}5.9 \\
(1.82)\end{array}$ & $\begin{array}{c}2.0 \\
\left(0.92^{\mathrm{a}}\right)\end{array}$ & * & $\begin{array}{l}(0.154) \\
\left(0.243^{\mathrm{a}}\right)\end{array}$ & 12 \\
\hline 8. Mean root length per plant $(\mathrm{cm})$ & 13.7 & 13.8 & 12.4 & 11.5 & $0.5^{\mathrm{a}}$ & $* * *$ & $\begin{array}{l}1.06 \\
1.68^{\mathrm{a}}\end{array}$ & 12 \\
\hline 9. Root weight (mg) & $\begin{array}{l}2355 \\
(7.73)\end{array}$ & $\begin{array}{c}1140 \\
(7.02)\end{array}$ & $\begin{array}{c}775 \\
(6.64)\end{array}$ & $\begin{array}{c}423 \\
(6.02)\end{array}$ & $\begin{array}{c}16 \\
\left(2.80^{\mathrm{a}}\right)\end{array}$ & $* * *$ & $\begin{array}{l}(0.144) \\
\left(0.228^{\mathrm{a}}\right)\end{array}$ & 12 \\
\hline 10. Sprout height $(\mathrm{cm})$ & 13.6 & 9.0 & 8.9 & 5.6 & $0.50^{\mathrm{a}}$ & $* * *$ & $\begin{array}{c}1.52 \\
2.41^{\mathrm{a}}\end{array}$ & 12 \\
\hline 11. Sprout weight (mg) & $\begin{array}{l}1340 \\
(7.18)\end{array}$ & $\begin{array}{c}985 \\
(6.86)\end{array}$ & $\begin{array}{c}817 \\
(6.67)\end{array}$ & $\begin{array}{c}425 \\
(6.02)\end{array}$ & $\begin{array}{c}20 \\
\left(3.04^{\mathrm{a}}\right)\end{array}$ & $* * *$ & $\begin{array}{c}(0.201) \\
\left(0.317^{\mathrm{a}}\right)\end{array}$ & 12 \\
\hline
\end{tabular}

$\mathrm{SED}^{\mathrm{a}}$ is to be used for comparison involving means with superscript ${ }^{\mathrm{a}}$ 
respectively. Cuttings with intact foliage showed only $22 \%$ sprouting. Delaying defoliation from 0 to 2,4 or 7 DAP increased the proportion of cutting with visible root initials from $6 \%$ to $63 \%, 69 \%$ and $72 \%$, respectively. By $2-3$ WAP, the cuttings defoliated on the day of planting showed high mortality. A basipetal drying of the stem was observed in the cuttings defoliated 4, 7 and 14 DAP, while 0 or 2 DAP defoliated cuttings showed an acropetal progression of decay. Cuttings with intact lamina throughout however, showed sustained shoot growth.

Delaying defoliation until after 14 DAP increased the proportion of cuttings with shoot and root growth (Fig. 4a). Survival was generally much lower when defoliation was earlier, although survival of cuttings defoliated 2 DAP was significantly greater than those defoliated 0,4 or 7 DAP. Only a low proportion of the cuttings defoliated 14 DAP maintained sprout and root growth after the defoliation. The cuttings defoliated 21 DAP showed survival similar to the intact leaf control.

Percent rooting (Fig. 4b) was worked out taking into account the cuttings that showed rooting at one WAP but failed to survive, and those with live or dead roots at 4 WAP. Leaf retention for just 2 days was enough to induce rooting in most cuttings (Fig. $4 b)$.

Surviving cuttings showed a significant $(P<0.01)$ increase in root number with leaf retention beyond 7 DAP, whereas root number of dead cuttings decreased after defoliation 14 DAP (Fig. 4c). The mean root length in surviving cuttings appeared to increase with the period of leaf retention (Fig. 4d). The remnants of roots in most of the dead cuttings from the defoliation 2, 4 and 7 DAP treatments measured between $0.5-3 \mathrm{~cm}$, depending on the duration of leaf retention, while in healthy cuttings, the roots measured about 5-8 cm (Fig. 4d). On the other hand, cuttings defoliated 14 DAP showed comparable root length in both healthy and dead cuttings (10.8 $\mathrm{cm}$ and $10.2 \mathrm{~cm}$ respectively).

The root wt per surviving cutting showed little increase with time of leaf retention until after 7 DAP, when it increased greatly (Fig. 4e). The pattern of response of sprout wt was more complex, but also increased as the period of leaf retention increased beyond 14 days (Fig. 4f).

\section{Effect of bringing the lamina closer to the rooting zone}

LAB cuttings showed delayed sprouting (Fig. 5a) and rooting (Fig. 5b) compared to LAT cuttings. By 4 WAP rooting of both types of cuttings was similar, but sprouting of LAB cuttings was significantly lower than LAT cuttings. Non-rooting as well as rooted but non-sprouting LAB cuttings displayed intense reddish pigmentation of leaf and drying of the exposed upper inter-nodal segment (Fig. 6).

When 1.5-2 month old ex vitro plants were cut back just above or below a node to confirm the inhibitory effect of exposed upper internode segment on sprouting, the latter that had long exposed upper inter-node similar to LAB cuttings exhibited delayed sprouting compared to those that had the minimum exposed upper inter-node (data not presented). Sprout ht depended on the number of sprouts developed, uninfluenced by the exposed upper internode.

\section{Discussion}

The present study has established the importance of leaf for the survival and good performance of
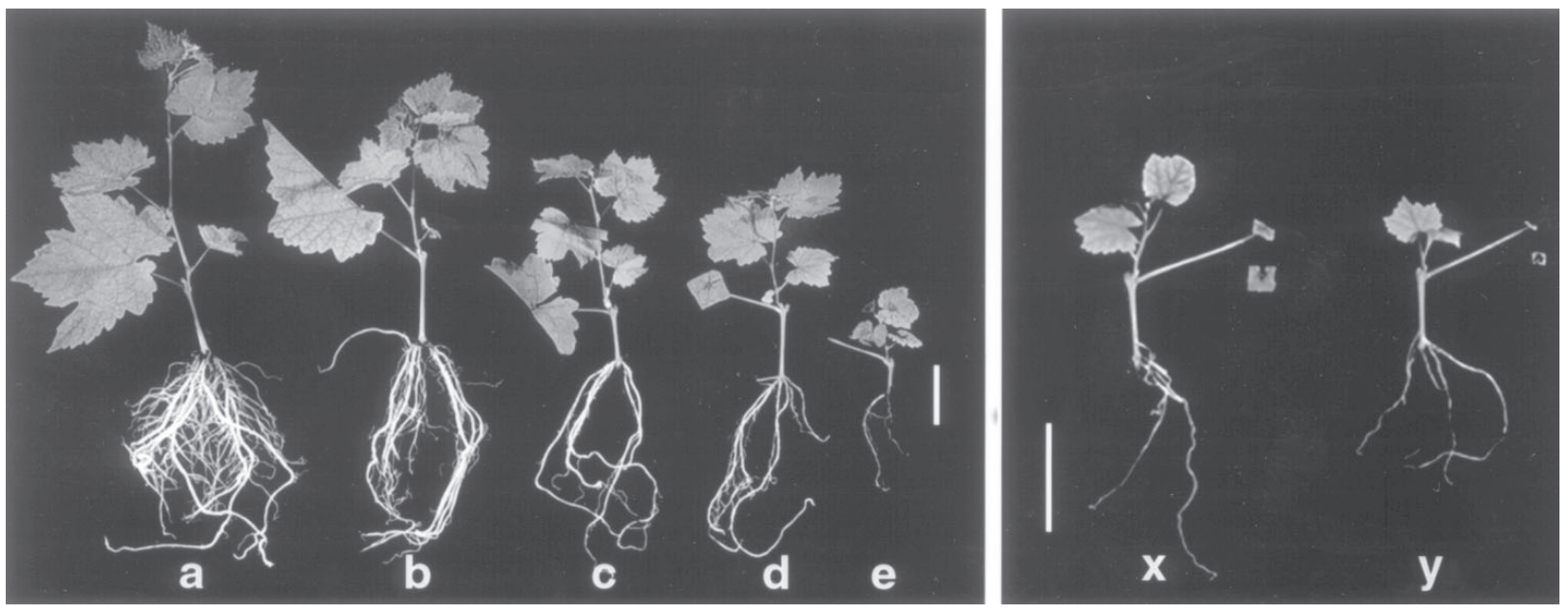

Fig. 3. Effect of decreasing leaf area of softwood cuttings (no IAA treatment) of grape on growth 4 wk after planting. Left: cutting with whole leaf (a), half longitudinal segment (b), half transverse segment (c), $1 \mathrm{~cm} \times 1 \mathrm{~cm}$ leaf segment (d) or defoliated cutting (e); Right: cutting with $0.5 \mathrm{~cm} \times 0.5 \mathrm{~cm}$ lamina $(\mathrm{x})$ or $0.1 \mathrm{~cm} \times 0.1 \mathrm{~cm}$ lamina at the point of petiole attachment $(\mathrm{y})(\mathrm{Bar}=3 \mathrm{~cm})$. 


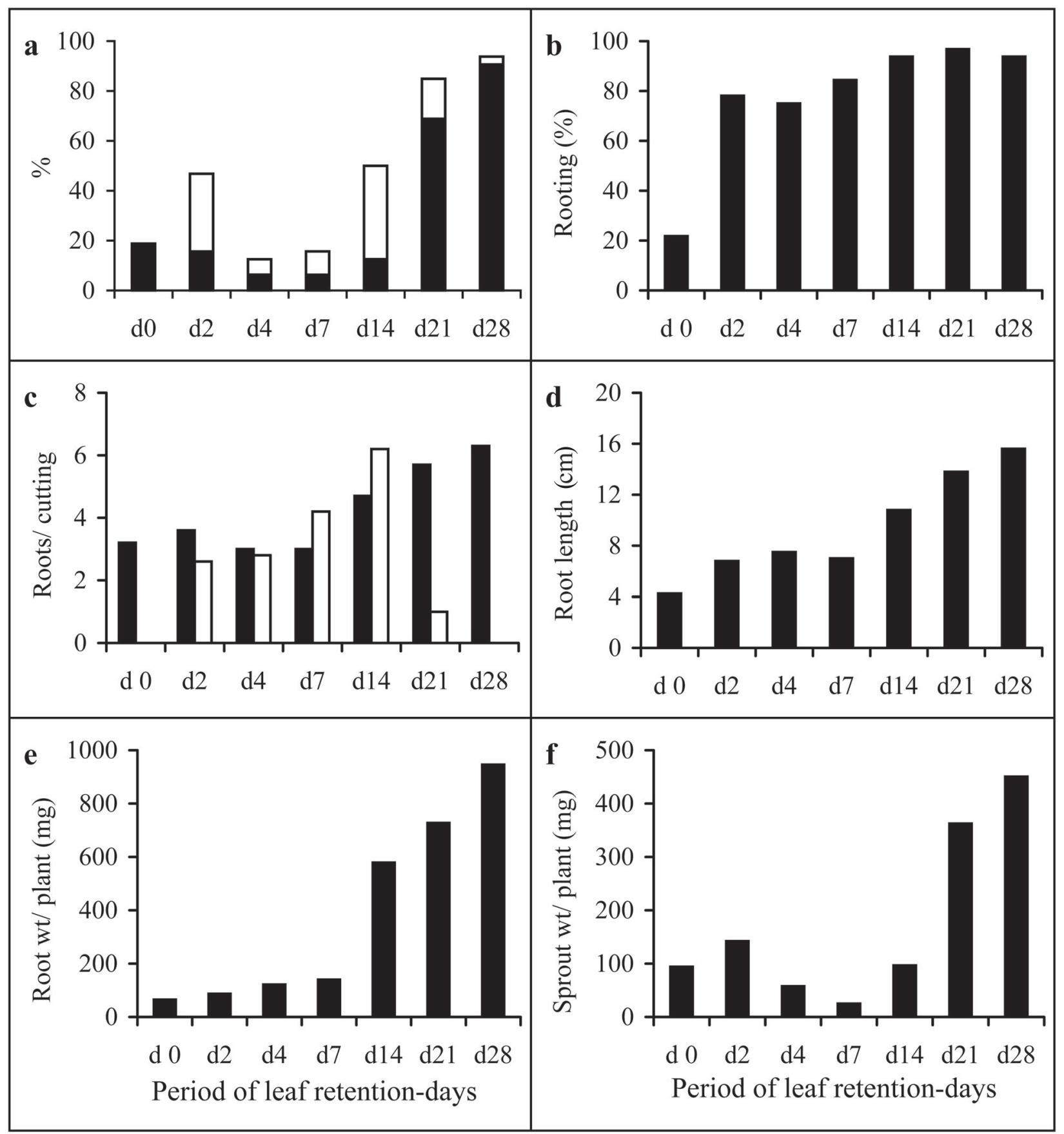

Fig. 4. Effect of leaf retention for varying periods (0 to 28 days) on percent survival and root and shoot growths in softwood cuttings (no IAA treatment) of grape at $4 \mathrm{wk}$ after planting.

a) Black shading $=$ cuttings with root and shoot growths. No shading $=$ survival

c) Black shading $=$ healthy plants. No shading = non-surviving cuttings

softwood cuttings of grape. In other plant systems, presence of leaf has been either essential for the survival of the cuttings (Wilson, 1994) or beneficial for rooting (Dore, 1965; Fournioux, 1997). The surviving leafless cuttings in isolated cases in the current study were relatively mature ones, which probably had some stored reserves. For grape microcuttings in vitro, presence of leaf was beneficial but not essential for their survival (Thomas, 1998) probably due to the ready supply of nutrients.

The determination of morphological variables of cuttings at planting warranted a destructive sampling, rendering them unsuitable for planting and hence the variables recorded on the original part of cutting at 4 WAP were used instead. A significant correlation existed between the wt of cuttings at planting and the morphological variables recorded at four WAP. The morphological variables were also highly and significantly inter-related. The greater the lamina area, the greater its wt, the wt of stem + petiole and the total wt of the cuttings. The lamina on an average constituted about $60 \%$ of the wt of 

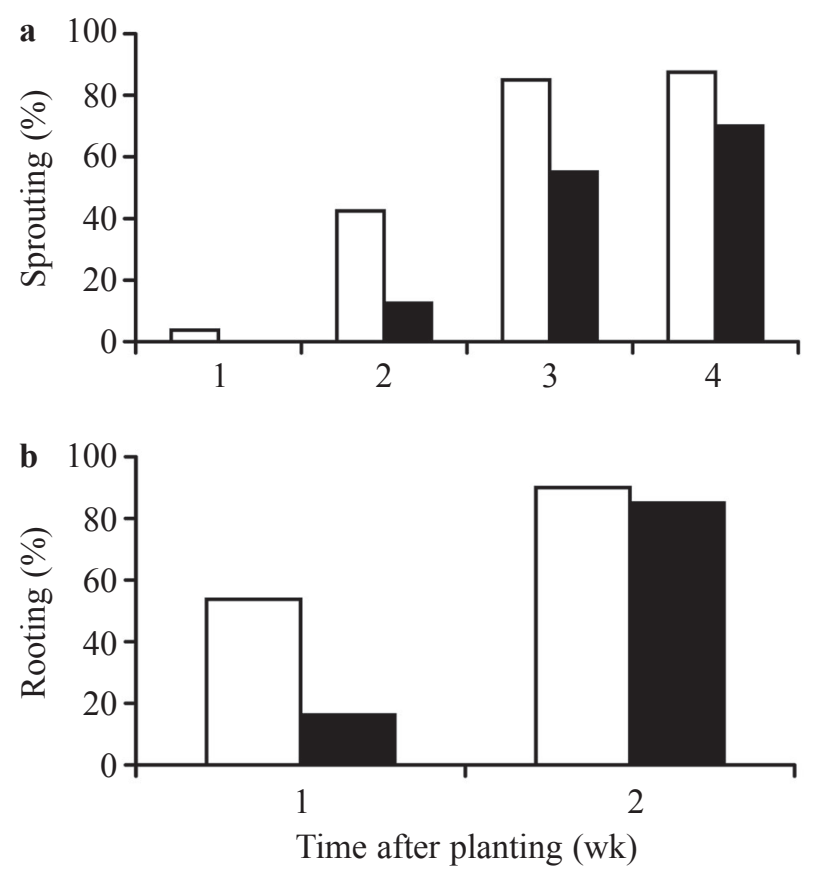

Fig. 5. Percent sprouting recorded at weekly interval (a) and percent rooting recorded at 1 or $4 \mathrm{wk}$ after planting in IAA-treated leaf at top (LAT) (no shading) and leaf at base (LAB) (black shading) softwood cuttings of grape (b).

the cutting. Amongst IAA- treated leafy cuttings, the fresh root wt was significantly correlated to the leaf area, total wt of cutting, and wt of leaf but to a lesser extent to the wt of stem + petiole tissue. A different sequence of significance was observed in IBA treated cuttings: total wt of cutting, wt of leaf, leaf area and wt of stem + petiole. In cuttings not treated with auxin where the internal auxin was enough to induce new growths, root wt was significantly correlated with leaf area, leaf wt and total wt of the cutting but not with stem + petiole wt. Thus, the leaf wt ranked higher than stem + petiole wt in all correlation analyses indicating that leaf played a more important role in regulation of root growth than the stem part. Considering that sprouting in leafy cuttings occurred after rooting and that a significant correlation existed between root and sprout wt, the better shoot growth in cuttings with larger leaf must be through the promotion of rooting by the lamina, similar to observations with grape microcuttings cultured in vitro (Thomas, 2000).

The promotive effects of leaf on rooting are generally attributed to the supply of auxin, photosynthate and rooting cofactors (Dore, 1965; Hartmann et al., 1997; Jarvis, 1986; Thomas, 1998; Wilson \& Van Staden, 1990). In cuttings not treated with IAA, the better root growth in leafy than defoliated cuttings is consistent with the role of leaf as a source of auxin. Reducing the leaf area as well as early defoliation triggered sprouting in stem

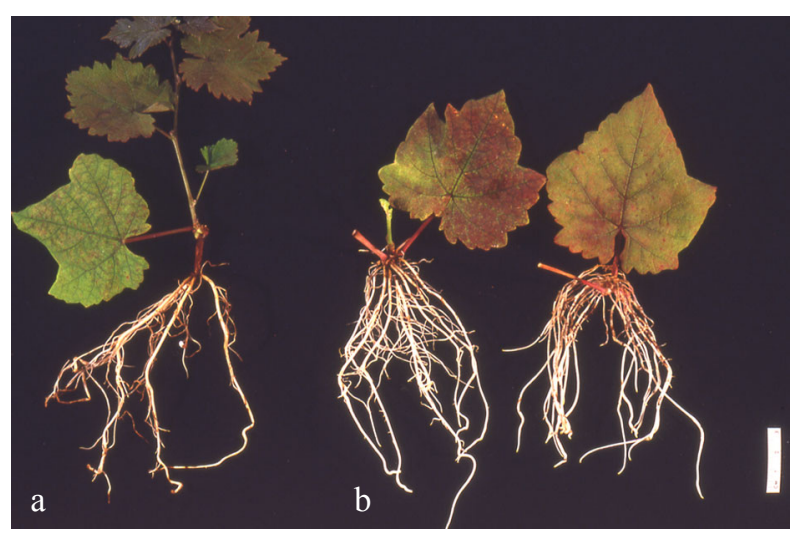

Fig. 6. Root and shoot growth in IAA-treated leaf at top (a) and leaf at base (b) softwood cuttings of grape at $4 \mathrm{wk}$ after planting.

cuttings, possibly in an effort to develop more photosynthetic capacity. In defoliated cuttings, a small sprout developed initially but that was not competent or sufficient to support the growth of the cutting. Shoot growth also might have an inhibitory effect on root growth (Davis \& Sankhla, 1988). Leafy cuttings on the other hand provide a continuous supply of photosynthates besides their reserves. Some studies suggest a major role of current photosynthate in adventitious root formation (Davis \& Potter, 1981; Davis, 1988) while others suggest that leaf serves as a source of carbohydrate reserves rather than current photosynthate (Van Overbeek et al., 1946; Hansen et al., 1978). The dry wt increase in leafy cuttings between the time of planting and 5 days later in the present study shows a positive net assimilation. This indicates that the leaf was a source of photosynthate even under the low photosynthetic photon flux density in this experiment.

Decreasing the leaf area of the cuttings did not affect their survival but the greater the area or wt of leaf, the better the root and shoot growth implying a contributory role in rooting by leaf possibly through the supply of auxin and carbohydrates. Retention of just a small piece of leaf was enough to induce rooting and to allow the survival of the cuttings, though at the cost of shoot and root vigour. The observation that leaf retention for just 2 days was enough to initiate rooting in most of the cuttings suggests that leaf tissue promotes induction of rooting. This is consistent with leaf acting as a source of rooting cofactors (Hartmann et al., 1997; Wilson \& Van Staden, 1990). There are many instances where the role of leaf in promotion of rooting could not be completely explained in terms of supply of nutritive factors or auxin (Dore, 1965; Thomas, 1998).

The sudden removal of leaf before the development of a sustainable shoot was highly detrimental for survival of the cuttings and the 
adverse effect was prominent in those defoliated 4, 7 or 14 DAP, during which period the cutting was more oriented to root growth. Leaf removal at any stage triggered sprout development. However, in the absence of continued carbohydrate supply and competition from growing roots, the shoot failed to sustain growth. The surviving cuttings of the 4 or 7 DAP defoliation treatments included those that had shown both rooting and sprouting at 1 WAP. The relatively good survival of cuttings defoliated 2 DAP was also possibly due to a synchrony of root and shoot growth induction. In in vitro studies too, defoliation of cuttings was found to induce early sprouting (Thomas, 1998). In the presence of leaf, on the other hand, rooting occurred before sprouting. Cuttings with relatively small leaves showed rooting and sprouting almost synchronously, while those with larger leaves exhibited early and vigorous root growth, delayed sprouting and subsequently a fast growing shoot (Thomas, 2000).

Although leaf had significant promotive effects on root and shoot growths, bringing the lamina closer to the rooting zone delayed both rooting and sprouting. Except for a similar observation in grape microcuttings cultured in vitro (Thomas, 2001), we could not trace any similar studies in the literature. In the observations under in vitro conditions, LAB microcuttings showed low survival as well as delayed rooting and sprouting. The low survival was attributable to the cut stem-node region coming in contact with the medium, which part was more sensitive to the constituents of the medium. On the other hand, delayed rooting and sprouting were attributable to an inhibitory effect by the exposed upper inter-nodal segment (Thomas, 2001). The high mortality of the LAB cuttings in vitro in the cited study due to their high sensitivity to the medium prevented the confirmation of the inhibitory effect of the exposed upper inter-node.

In the present study, the observations of LAB cuttings and of delayed sprouting in pruning experiments with the retention of long exposed upper inter-node suggested the operation of an inhibitory effect. This is probably due to the production of toxic/inhibitory substances by non-functional stem tissue. However, LAB cuttings that did not show drying of stem exhibited root growth comparable to or better than that in LAT cuttings. The shoot growth lagged behind initially on account of delayed sprouting compared to LAT cuttings. In other words, the inhibitory effect due to exposed upper inter-node was more reflected in new shoot growth. The high reddish or purple pigmentation of leaf and stem observed in late rooting or non-rooting LAB cuttings ruled out the possible involvement of anthocyanins in rooting (Bachelard \& Stowe, 1962) similar to observations under in vitro conditions (Thomas, 2001). This could be related to nutrient stress induced by delayed rooting as seen with root removed plantlets at ex vitro planting (Thomas \& Ravindra, 1997).

The observations in the present study help to exploit softwood leafy cuttings of grape for rapid propagation of elite cultivars with or without auxin treatment. The tender upper parts of the stock shoots as well as the basal region with smaller leaves were less suitable for use in propagation (Thomas \& Schiefelbein, 2001). The tissue culture derived stock plants in the cited study showed adult characteristics such as distichous phyllotaxy, tri-lobed leaves and normal N0-N1-N2 pattern of tendril production within two months of in vivo planting (Thomas, 1999; Thomas \& Schiefelbein, 2001). Juvenile characters such as spiral phyllotaxy, four to five deep lobed leaves and lack of tendril (Weaver, 1976; Mullins et al., 1979) which are reportedly associated with micropropagated plants (Martinez \& Mantilla, 1995) were not seen. The plants propagated further using softwood cuttings in vivo showed good root and shoot growth within two months after planting and they continued to display adult, rather than juvenile characteristics. The lamina of leafy cuttings physically restricts the number of cuttings that can be planted per unit area. This limitation could be overcome by removing $50 \%$ leaf area of the cuttings between the point of petiole attachment and tip. Although this affected root and shoot growth, it nevertheless ensured healthy plants.

The differential rooting and sprouting of leafy and defoliated softwood cuttings can be used as an experimental system for investigations into the molecular bases of root and shoot growth. This type of study is not feasible with mature or hardwood cuttings of grape, as they are intractable to nucleic acid isolation. Employing differential display, a number of differentials corresponding to mRNAs induced during rooting phase were identified (Thomas \& Schiefelbein, 2002a). Some of these mRNAs, including an actin depolymerising factor gene and two proline-rich protein genes that showed over-expression in leafy cuttings compared with defoliated cuttings, have been cloned and characterised based on the information generated in this study (Thomas \& Schiefelbein, 2002b; Thomas et al., 2003). The differential rooting and sprouting of leafy and defoliated softwood cuttings could also be used to address the problem of recalcitrance to rooting in stem cuttings without the interference from genotypic effects when easy- and difficult-to-root cultivars are used.

\section{Acknowledgements}

Pious Thomas acknowledges the award of Overseas Associateship by the Department of Biotechnology, Ministry of Science and Technology, 
Government of India which facilitated the exchange visit programme. The supply of Arka Neelamani grape culture from the Indian Institute of Horticultural Research (ICAR), Bangalore, India is acknowledged.

\section{References}

Bachelard E P, Stowe B B. 1962. A possible link between root initiation and anthocyanin formation. Nature 194:209-210.

Barlass M, Skene K G M. 1980. Studies on fragmented shoot apex of grapevine. II. Factors affecting growth and differentiation in vitro. Journal of Experimental Botany 31:489-495.

Davis T D. 1988. Photosynthesis during adventitious rooting. In Adventitious Root Formation in Cuttings, pp. 79-87. Eds T D Davis, B E Haissig and N Sankhla. Portland: Dioscorides Press.

Davis T D, Potter J R. 1981. Current photosynthate as a limiting factor in adventitious root formation on leafy pea cuttings. Journal of the American Society for Horticultural Science 106:278-282.

Davis T D, Sankhla N. 1988. Effect of shoot growth retardants and inhibitors on adventitious rooting. In Adventitious Root Formation in Cuttings, pp. 174-184. Eds T D Davis, B E Haissig and N Sankhla. Portland: Dioscorides Press.

Dore J. 1965. Physiology of regeneration in cormophytes. In Encyclopaedia of Plant Physiology Vol. 15/2, pp. 1-91. Ed. W Ruhland. Berlin: Springer-Verlag.

Fournioux J C. 1997. Adult leaves of grapevine cuttings stimulate rhizogenesis. Vitis 36:49-50.

Hansen J, Strömquist L H, Ericsson A. 1978. Influence of the irradiance on carbohydrate content and rooting of cuttings of pine seedlings. Plant Physiology 61:975-979.

Hartmann H T, Kester D E, Davies F T, Geneve R L. 1997. Plant Propagation- Principles and Practices. $6^{\text {th }}$ Edn. New Jersey: Prentice Hall.

Jarvis B C. 1986. Endogenous control of adventitious rooting in non-woody cuttings. In New Root Formation in Plants and Cuttings, pp. 191-222. Ed. M B Jackson. Dordrecht: Martinus Nijhoff Publishers.

Martinez M C, Mantilla J L G. 1995. Morphological and yield comparison between Vitis vinifera L. cv. Albariño grown from cuttings and from in vitro propagation. American Journal of Enology and Viticulture 46:195-203.

Mullins M G, Nair Y, Sampet P. 1979. Rejuvenation in vitro: Induction of juvenile characters in an adult clone of Vitis vinifera L. Annals of Botany 44:623-627.

Murashige T, Skoog F. 1962. A revised medium for rapid growth and bioassays with tobacco tissue cultures. Physiologia Plantarum 15:473-497.
Thomas P. 1997. Increase in clonal propagation of 'Arka Neelamani' grape (Vitis vinifera L.) through induction of axillaries in in vitro layering technique. Indian Journal of Agricultural Sciences 67:594-596.

Thomas P. 1998. Contribution of leaf lamina of grape nodal microcuttings to rooting, root vigour and plantlet growth in vitro. Journal of Plant Physiology 153:727-732.

Thomas P. 1999. Relationship between tissue growth, $\mathrm{CO}_{2}$ level and tendril formation during in vitro culture of grape (Vitis vinifera L.). Vitis 38:25-29.

Thomas P. 2000. Microcutting leaf area, weight, and position on the stock shoot influence root vigour, shoot growth and incidence of shoot tip necrosis in grape plantlets in vitro. Plant Cell Tissue and Organ Culture 61:189-198.

Thomas P. 2001. Leaf number and position effects on the survival and performance of grape microcuttings in vitro, and the sensitivity of the cut nodal region to the medium. Plant Cell Tissue and Organ Culture 65:129-139.

Thomas P, Ravindra M B. 1997. Effect of pruning or removal of in vitro formed roots on ex vitro root regeneration and growth in micropropagated grapes. Plant Cell Tissue and Organ Culture 51:177-180.

Thomas P, Schiefelbein J W. 2001. Combined in vitro and in vivo propagation for rapid multiplication of grapevine cv. Arka Neelamani. HortScience 36:1107-1110.

Thomas P, Schiefelbein J W. 2002a. An improved method for purification of RNA from stem tissue of grapevine and its use in mRNA profiling. American Journal of Enology and Viticulture 53:231-234.

Thomas P, Schiefelbein J W. 2002b. Cloning and characterization of an actin depolymerizing factor gene from grape (Vitis vinifera L.) expressed during rooting in stem cuttings. Plant Science 162:283-288.

Thomas P, Lee M M, Schiefelbein J W. 2003. Molecular identification of proline-rich protein genes induced during root formation in grape (Vitis vinifera L.) stem cuttings. Plant Cell and Environment 26:1497-1504.

Van Overbeek J, Gordon S A, Gregory L E. 1946. An analysis of the function of the leaf in the process of root formation in cuttings. American Journal of Botany 33:100-107.

Weaver R J. 1976. Grape Growing. New York: John Wiley and Sons. $371 \mathrm{pp}$.

Wilson P J. 1994. Contributions of the leaves and axillary shoots to rooting in Eucalyptus grandis Hill ex Maid. stem cuttings. Journal of Horticultural Science 69:999-1007.

Wilson P J, Van Staden J. 1990. Rhizocaline, rooting cofactors, and the concept of promoters and inhibitors of adventitious rooting - a review. Annals of Botany 66:479490. 